\title{
EFEITOS DA SALINIDADE DA ÁGUA DE IRRIGAÇÃO NA BROTAÇÃO E DESENVOLVIMENTO INICIAL DA CANA-DE-AÇÚCAR (Saccharum spp) E EM SOLOS COM DIFERENTES NÍVEIS TEXTURAIS
}

\author{
Effects of irrigation water salinity upon the sprouting and initial development of sugar cane \\ (Saccharum spp) and on soils with different textural levels
}

\author{
Márcio José de Santana ${ }^{1}$, Jacinto de Assunção Carvalho ${ }^{2}$, Kleber Junio de Souza ${ }^{3}$, \\ Alexandre Marcio Gomes de Sousa ${ }^{3}$, Carolina Lara Vasconcelos ${ }^{4}$, Luiz Antônio de Bastos Andrade ${ }^{5}$
}

\begin{abstract}
RESUMO
Foram avaliados os efeitos de diferentes concentrações de sal na água de irrigação, no desenvolvimento inicial da cana-deaçúcar, cultivar SP80-1842, cultivada em solos com diferentes níveis texturais. O experimento foi conduzido em casa-de-vegetação do Departamento de Engenharia da Universidade Federal de Lavras, em Lavras, MG. A finalidade do cultivo em ambiente protegido foi de possibilitar os tratamentos de níveis de sal na água de irrigação, sem a interferência das precipitações pluviométricas. Os tratamentos consistiram em quatro níveis de salinidade da água de irrigação (condutividade elétrica de 0,$10 ; 2,0 ; 5,0$ e $8,0 \mathrm{dS} \mathrm{m}^{-1}$ ), e três classes texturais de solo (texturas arenosa, média e argilosa), totalizando doze tratamentos e caracterizando um delineamento inteiramente casualizado (DIC), em esquema fatorial de 4 X 3, com oito repetições. No início e após experimentação, foram coletadas amostras dos solos para obtenção da condutividade elétrica do extrato saturado, retratando o efeito da salinidade da água de irrigação sobre os tipos de solo. Aos 38 dias após plantio das gemas, obteve-se a massa seca da raiz e da parte aérea, sendo que, durante a experimentação foram contados, diariamente, o número de gemas que brotavam em cada vaso. Os resultados mostraram que a cana-de-açúcar, cultivar SP80-1842, é sensível a salinidade da água de irrigação, durante sua fase inicial de cultivo. Todos os parâmetros vegetativos foram reduzidos com aumento da salinidade da água de irrigação. Houve um aumento da salinidade do solo em virtude do aumento da condutividade elétrica da água de irrigação. As maiores médias dessas variáveis foram obtidas no solo de textura média.
\end{abstract}

Termos para indexação: Salinidade da água, cana-de-açúcar, irrigação.

\section{ABSTRACT}

The different concentrations of salt in the irrigation water on the initial development of sugar cane, cultivar SP80-1842, grown in soils with different textural levels were evaluated. The experiment was conducted in a greenhouse of the Agricultural Engineering Department of the Federal University of Lavras, in Lavras, MG. The purpose of the protected environment cultivation was to make the treatments of salt levels in the irrigation water possible, without the interference of rainfalls. The treatments consisted of four levels of salinity of the irrigation water (electric conductivity of $\left(0.10 ; 2.0 ; 5.0\right.$ and $\left.8.0 \mathrm{dS} \mathrm{m}^{-1}\right)$, and three textural classes of soil e (sandy, medium and clayey), amounting to twelve treatments and characterizing a completely randomized design (CRD), in a 4X3 factorial scheme, with eight replicates. At the biggining and after the experimentation, soils' samples were collected in order to obtaining electric conductivity of the saturated extract, picturing the effect of salinity of the irrigation water on the sorts of soils. On 38 days after planting of the buds, the root and shoot dry matter was obtained and over the experimentation were counted daily the number of buds which sprouted in each pot. Results showed that sugar cane, cultivar SP80-1842, is sensitive to irrigation water salinity, during its initial phase of cultivation. All the vegetative parameters were reduced as the salinity of irrigation water increased. An increase of soil salinity was found after experimentation, with growing levels of slat in the water, redounding to fall in the quoted variables. The highest means of those variables were obtained in the medium textured soil.

Index terms: Water salinity, sugar cane, irrigation.

(Recebido em 8 de setembro de 2005 e aprovado em 7 de agosto de 2006)

\section{INTRODUÇÃO}

A cana-de-açúcar desenvolve-se bem sob estação quente e longa (com temperaturas médias diárias entre 22 e $30^{\circ} \mathrm{C}$ ), com incidência de radiação alta e umidade relativa adequada, seguida de período seco, ensolarado e medianamente frio durante a fase de maturação e colheita. Apresenta crescimento lento no início, aumentando gradualmente até atingir a taxa máxima de crescimento,

\footnotetext{
Engenheiro Agrônomo, Professor Adjunto I do Centro Federal de Educação Tecnológica/CEFET - 38001-970 - Uberaba, MG marciosantana@cefetuberaba.edu.br

2Professor Associado I (bolsista CNPq) - Departamento de Engenharia/DEG - Universidade Federal de Lavras/UFLA - Cx. P. 3037 - $37200-000$ - Lavras, MG jacintoc@ufla.br

${ }^{3}$ Engenheiro Agrícola pelo Departamento de Engenharia/DEG - Universidade Federal de Lavras/UFLA - Cx. P. 3037 - $37200-000$ - Lavras, MG alexisagricola@bol.com.br

${ }^{4}$ Engenheira Agrônoma - Rua Farnesi Maciel, 104 - Patos de Minas, MG - biosferaambiental@terra.com.br

${ }^{5}$ Professor Titular do Departamento de Agricultura/DAG - Universidade Federal de Lavras/UFLA - Cx. P. 3037 - $37200-000$ - Lavras, MG laba@ufla.br
} 
diminuindo em seguida, à medida que a cana começa a amadurecer. Dos tratos culturais, a irrigação funciona como um fator imprescindível para a garantia de produção com qualidade e aumento da produtividade, principalmente em regiões onde há irregularidade na distribuição das chuvas. A cana irrigada apresenta maior crescimento, densidade de colmos e índice de área foliar, e valores de teor de açúcar em comparação ao cultivo sem irrigação.

O uso da irrigação tem contribuído, significativamente, para o aumento da produtividade agrícola além da incorporação, ao sistema produtivo, de áreas cujo potencial para exploração da agricultura é limitado, em razão de seus regimes pluviais. Por outro lado, a irrigação tem causado alguns problemas ao meio ambiente. Dentre eles, destaca-se o uso inadequado da água salina e/ou sódica resultando na perda da capacidade produtiva do solo. A salinidade da água provoca alterações nas propriedades físico-químicas do solo (RHOADES et al., 1992, citados por LIMA, 1998).

Em geral, a agricultura irrigada depende tanto da quantidade quanto da qualidade da água. Até o início do século XX, devido à disponibilidade de água de boa qualidade e de fácil utilização, não havia a preocupação com a preservação e uso racional da água.. A partir deste período, com o aumento de consumo de águas de qualidade houve uma redução da disponibilidade destas, provocando, conseqüentemente, a necessidade de se usar águas de qualidade inferior (AYERS \& WESTCOT, 1991).

Dentre as características que determina a qualidade da água para a irrigação, a concentração de sais solúveis ou salinidade é um fator limitante ao desenvolvimento de algumas culturas (BERNARDO, 1996).

O objetivo principal da irrigação é proporcionar às culturas no momento oportuno, a quantidade de água necessária para seu ótimo crescimento e, assim, evitar a diminuição dos rendimentos, provocada pela falta de água durante as etapas de desenvolvimento sensíveis à escassez. Com as irrigações, no entanto, os sais contidos na água acumulam-se na zona radicular, diminuindo a disponibilidade de água e acelerando sua escassez. A compreensão do processo de salinização, permite encontrar formas de evitar seus efeitos e diminuir a probabilidade de redução de seus rendimentos (AYERS \& WESTCOT, 1991)

Os principais problemas causados pela salinização do solo são a redução do potencial osmótico da solução do solo, diminuindo sua disponibilidade de água e acentuando a toxicidade de certos íons às plantas (BERNARDO, 1996).
A acumulação de sais na rizosfera prejudica o crescimento e desenvolvimento das culturas, provocando um decréscimo de produtividade e, em casos mais severos, pode levar a um colapso da produção agrícola. Isto ocorre em razão da elevação do potencial osmótico da solução do solo, por efeitos tóxicos dos íons específicos e alteração das condições físicas e químicas do solo (LIMA, 1998).

Os sais são transportados pelas águas de irrigação e depositados no solo, onde se acumulam à medida que a água se evapora ou é consumida pelas culturas. Os sais do solo e da água reduzem a disponibilidade da água para as plantas, a tal ponto que afetam os rendimentos das culturas. Nem todas as culturas respondem igualmente à salinidade, algumas produzem rendimentos aceitáveis a níveis altos de salinidade e outras são sensíveis a níveis relativamente baixos. Esta diferença deve-se à melhor capacidade de adaptação osmótica que algumas culturas tem, o que permite absorver, mesmos em condições de salinidade, maior quantidade de água (AYERS \& WESTCOT, 1991).

Solos normais podem se tornar improdutivos se receberam sais solúveis em excesso devido a irrigações mal conduzidas com águas salinas. Mesmo com um bom controle da qualidade da água de irrigação (o que raramente é feito na prática) há um contínuo resíduo de sais no solo (SOUZA, 1995).

A cana-de-açúcar é considerada moderadamente sensível à salinidade, sendo que a diminuição do rendimento pode chegar a $50 \%$ com solos de condutividade elétrica de $10,4 \mathrm{dS} \mathrm{m}^{-1}$.

Dependendo da estrutura e composição química, os solos retêm mais ou menos nutrientes e sais provenientes da água de irrigação. São necessários estudos regionais nas diversas situações de cultivos, avaliando as respostas das culturas à salinidade da água em diferentes tipos de solos. Assim propôs-se com este trabalho, estudar os efeitos da salinidade da água de irrigação em fase inicial da cultura da cana-de-açúcar, cultivada em diferentes tipos de solos quanto à textura

\section{MATERIAL E MÉTODOS}

O experimento foi conduzido em casa-de-vegetação junto ao Laboratório de Hidráulica da UFLA, em Lavras, MG, a 910 metros de altitude, $21^{\circ} 14^{\prime} \mathrm{S}$ de latitude e $45^{\circ}$ $00^{\prime} \mathrm{W}$ de longitude. Em vasos de polietileno com capacidade para $3 \mathrm{dm}^{3}$, foram plantadas seis gemas de cana-de-açúcar, por vaso, extraídas da cultivar SP80-1842, e irrigadas até os 38 dias após plantio. O delineamento experimental foi o inteiramente casualizado (DIC) em um esquema fatorial de 
4 X 3, sendo quatro níveis de salinidade da água de irrigação (condutividade elétrica de 0,$10 ; 2,0 ; 5,0$ e 8,0 dS $\mathrm{m}^{-1}$ ), e três classes texturais de solo (texturas arenosa, média e argilosa), totalizando doze tratamentos e oito repetições.

As irrigações foram feitas a cada dois dias, e, o volume percolado era coletado por meio de drenos instalados no fundo dos vasos. Com os volumes de irrigação e de drenagem, era feito, então, o balanço de água no solo, conforme Carvalho et al. (2001) e Gervásio et al. (2000), sendo: ET = I - D, em que ET é a evapotranspiração da cultura em questão; I é a água adicionada e D é a água drenada.

O preparo das águas (soluções) foi feito com o sal $\mathrm{NaCl}$. Em laboratório foi determinada anteriormente à variação da condutividade elétrica da solução contendo diferentes concentrações do sal, obtendo uma equação após a análise de regressão (1).

$$
\mathrm{CE}=0,10586+2,7323 \mathrm{C}_{\mathrm{NaCl}}
$$

sendo:

$\mathrm{CE}=$ condutividade elétrica da solução $\left(\mathrm{dS} \mathrm{m}^{-1}\right)$; $\mathrm{C}_{\mathrm{NaCl}}=$ quantidade de $\mathrm{NaCl}\left(\mathrm{mg} \mathrm{L}^{-1}\right)$.

Na Figura 1, mostra-se como foi a variação da condutividade elétrica com o aumento da salinidade da água.

A equação 1 foi utilizada para preparo das soluções, as quais foram renovadas semanalmente e armazenadas em local fresco e sombreado, a fim de evitar alterações do seu valor por possíveis evaporações e variações da temperatura (GERVÁSIO et al., 2000).

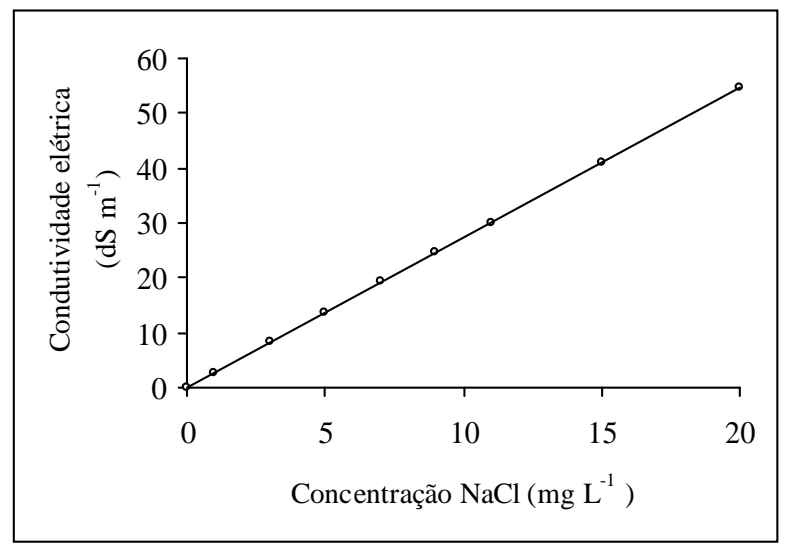

FIGURA 1 - Condutividade elétrica em função dos teores de $\mathrm{NaCl}$.
O início do experimento caracterizou-se por elevar o solo dos vasos à capacidade de campo; para isto saturaram-se os solos com água sem sal, envolvendo-os individualmente com plástico, de forma a forçar a perda de água apenas por drenagem. Quando cessou a drenagem (aproximadamente dois dias) retiraram-se os plásticos e procedeu-se o plantio das gemas.

O preparo das gemas consistiu em retirá-las com um extrator e tratá-las com um fungicida horas antes do plantio.

Ao final da experimentação foram obtidas as massas secas das raízes e da parte aérea de todas as plantas. Durante esse período foram contadas as gemas, caracterizando o número de brotações em cada parcela (vaso).

No início e após experimentação foram obtidas informações da fertilidade do solo. Na Tabela 1 estão apresentados os valores de alguns nutrientes encontrados em cada solo antes da experimentação.

Determinaram-se os valores da condutividade elétrica do extrato saturado do solo (CEes), sendo um parâmetro de medida da salinidade do solo. Em laboratório essas amostras passaram por uma preparação, consistindo basicamente em misturar terra fina seca ao ar (TFSA) com água destilada de maneira a obter a "pasta saturada". Esta pasta foi então, após repouso, colocada num funil de extração com papel de filtro de alta retenção. Aplicou-se sucção coletando todo o extrato. A determinação de CE foi feita logo após a preparação do extrato, sendo o resultado expresso em temperatura padrão de $25^{\circ} \mathrm{C}$ (RICHARDS, 1954). Para isso multiplicou-se a $C_{t}$ medida a uma temperatura $t^{\circ} \mathrm{C}$ pelo fator $\mathrm{f}_{\mathrm{t}}$ para transformá-las na $\mathrm{CE}$ correspondente a $25^{\circ} \mathrm{C}$ (Tabela 2$)$.

\section{RESULTADOS E DISCUSSÃO}

Houve redução na evapotranspiração da cana-deaçúcar em sua fase inicial com o aumento da condutividade elétrica da água de irrigação, conforme Figura 2. Ainda pela mesma figura, nota-se que as menores reduções de evapotranspiração aconteceram no solo de textura argilosa. Houve uma redução da evapotranspiração real da cultura, em relação à sua evapotranspiração potencial, quando a irrigação foi feita utilizando água com concentração salina de $8,0 \mathrm{dS} \mathrm{m}^{-1}$ no solo arenoso (20,08\%). Esse resultado concorda com o obtido por diversos autores; sendo que Gervásio et al. (2000) observaram que diferentes concentrações maiores de sal na água de irrigação reduziram a evapotranspiração da alface americana. Marinho et al. (1998), ao estudarem diferentes 
TABELA 1 - Teores de alguns nutrientes no início do experimento UFLA, Lavras, MG.

\begin{tabular}{lccc}
\hline & & Classes texturais & \\
\hline Características & Arenoso & Média & Argilosa \\
\hline $\mathrm{pH} \mathrm{em} \mathrm{H} \mathrm{H}_{2} \mathrm{O}$ & 5,7 & 5,8 & 6,1 \\
$\mathrm{P}\left(\mathrm{mg} \mathrm{dm}^{3-}\right)$ & 125,2 & 153,9 & 136,5 \\
$\mathrm{~K}\left(\mathrm{mg} \mathrm{dm}^{3-}\right)$ & 59,0 & 99,0 & 97,0 \\
$\mathrm{Na}^{+}\left(\mathrm{mg} \mathrm{dm}^{3-}\right)$ & 7,4 & 12,9 & 9,2 \\
$\mathrm{Ca}^{+2}\left(\mathrm{cmol}_{\mathrm{c}} / \mathrm{dm}^{3}\right)$ & 5,8 & 11,0 & 7,7 \\
$\mathrm{Mg}^{+2}\left(\mathrm{cmol}_{\mathrm{c}} / \mathrm{dm}^{3}\right)$ & 0,8 & 4,5 & 1,4 \\
$\mathrm{Al}^{+3}\left(\mathrm{cmol}_{\mathrm{c}} / \mathrm{dm}^{3}\right)$ & 0,1 & 0,1 & 0,1 \\
$* \mathrm{SB}\left(\mathrm{cmol}_{\mathrm{c}} / \mathrm{dm}^{3}\right)$ & 6,8 & 15,8 & 9,4 \\
$* \mathrm{t}\left(\mathrm{cmol}_{\mathrm{c}} / \mathrm{dm}^{3}\right)$ & 6,9 & 15,9 & 9,5 \\
$* \mathrm{~T}\left(\mathrm{cmol}_{\mathrm{c}} / \mathrm{dm}^{3}\right)$ & 8,9 & 19,0 & 11,3 \\
$* \mathrm{~V}(\%)$ & 76,4 & 83,2 & 83,2 \\
\hline
\end{tabular}

*SB = soma de bases trocáveis; *t= capacidade de troca catiônica efetiva; * T= capacidade de troca catiônica a pH 7,0;

* V = índice de saturação por bases.

TABELA 2 - Fator de correção da condutividade elétrica, em função da temperatura $\left(\mathrm{CE}_{25}=\mathrm{CE}_{\mathrm{t}} * \mathrm{f}_{\mathrm{t}}\right)$.

\begin{tabular}{c|ccccccccc}
\hline $\mathrm{T}^{\circ} \mathrm{C}$ & 15 & 17 & 19 & 21 & 23 & 25 & 27 & 29 & 31 \\
$\mathrm{f}_{\mathrm{t}}$ & 1,247 & 1,189 & 1,136 & 1,087 & 1,043 & 1,000 & 0,960 & 0,925 & 0,890 \\
\hline
\end{tabular}

concentrações de sal na água no desenvolvimento do abacaxizeiro chegaram a resultados semelhantes como acontecido com Santos (1990), com a cultura da bananeira em estágio inicial de crescimento. Já Borella (1986) constatou que, com o aumento da condutividade elétrica da água de irrigação, houve um decréscimo no consumo de água, obedecendo a uma função linear, quando se irrigou o feijoeiro com diferentes lâminas de lixiviação e concentrações salinas.

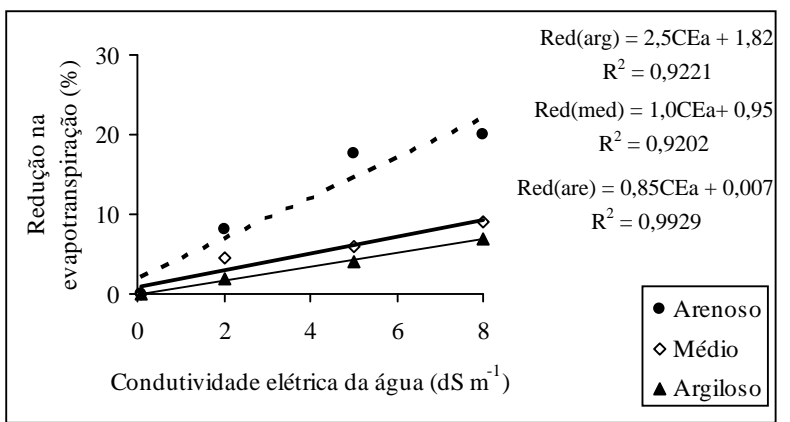

FIGURA 2 - Redução na evapotranspiração da cana-deaçúcar, durante a fase inicial de desenvolvimento, em função da CEa, para os diferentes tipos de solos.
Com o aumento da condutividade elétrica da água de irrigação houve um incremento na condutividade elétrica do extrato de saturação (CEes), ao final da experimentação(Figura 3). Os maiores valores de CEes foram alcançados no solo de textura argilosa, sendo de 2,26; 4,86; 6,89 e 10,25 dS m $\mathrm{d}^{-1}$ para as águas de 0,$1 ; 2,0 ; 5,0$ e $8,0 \mathrm{dS} \mathrm{m}^{-1}$, respectivamente. Souza (1995) observou uma evolução na CEes sendo proporcional aos tratamentos de excesso de sal na água de irrigação, em um solo cultivado com o feijoeiro. Outros autores que constataram resultado semelhante foram Blanco (1999), Borella (1986) e Gervásio et al. (2000), em solos conduzindo as culturas do feijoeiro, alface americana e pepino enxertado, respectivamente.

A massa seca das raízes da cana-de-açúcar em fase inicial de desenvolvimento foi afetada pelos níveis de sal na água de irrigação, onde os menores pesos foram encontrados quando irrigou-se com água de maior nível salino e em textura arenosa. As maiores massas secas das raízes foram encontradas em solos com textura média (Figura 4), a mesma tendência foi constatada para as massas secas da parte aérea, conforme Figura 5. É evidenciado que em um solo de textura argilosa obtiveram-se maiores retenções de sal elevando a CEes redundando em queda das variáveis vegetativas. Por outro lado, o solo de textura 
arenosa possivelmente proporciona maiores lixiviações de sais sendo esses às vezes nutrientes, levando também a valores baixos das variáveis vegetativas.

Não houve diferença significativa entre a interação de salinidade da água de irrigação e classes texturais para a brotação. Isoladamente houve efeito do nível de sal na

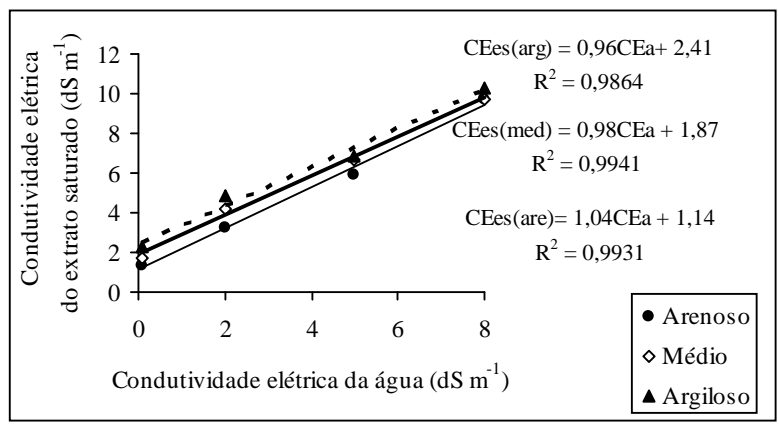

FIGURA 3 - Condutividade elétrica do extrato de saturação (CEes) em função da salinidade da água de irrigação (CEa).

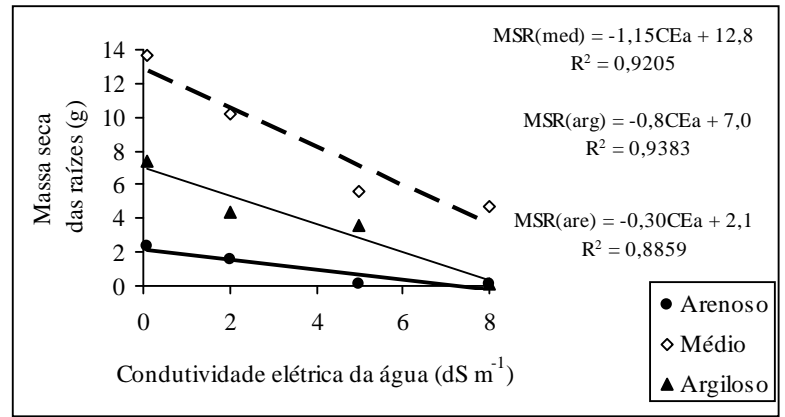

FIGURA 4 - Massa seca das raízes da cana-de-açúcar em função da salinidade da água de irrigação.

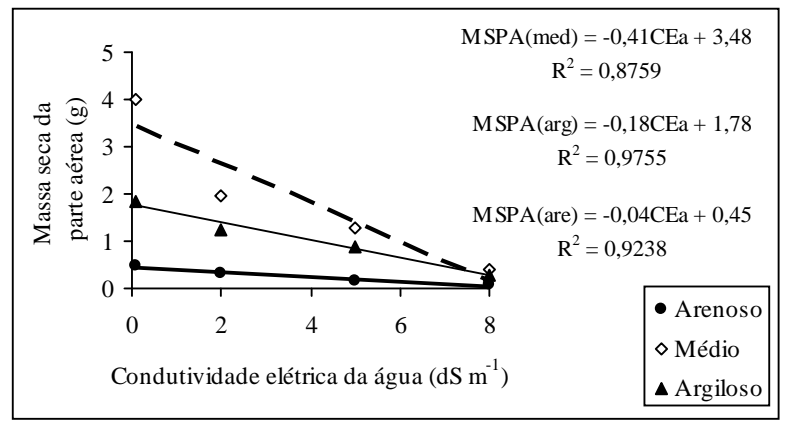

FIGURA 5 - Massa seca da parte aérea da cana-de-açúcar em função da salinidade da água de irrigação. água de irrigação, bem como, das classes. Na Figura 6, mostra-se a tendência de decréscimo na porcentagem de brotação da cana-de-açúcar em função da salinidade da água de irrigação. É no solo de textura média que se tem o maior valor de brotação, como é mostrado na Tabela 3 .

Nas Tabelas 4, 5 e 6 mostram-se as concentrações totais de alguns nutrientes encontrados no solo de todos os tratamentos, ao final da experimentação. Independentemente da textura do solo, com o aumento da salinidade da água de irrigação houve um aumento do sódio no solo, concordando com o encontrado nos trabalhos desenvolvidos por Blanco (1999) e Medeiros (1998). O maior teor de sódio foi encontrado em solos com textura argilosa e irrigado com águas de $8,0 \mathrm{dS} \mathrm{m}^{-1}$. Quando a cultura foi conduzida em um solo de textura média, os valores desse elemento encontrado no solo foram de 27,6; 463,7; 883,2 e 1295,4 $\mathrm{mg} \mathrm{dm}^{-3}$, para as águas de 0,$1 ; 2,0 ; 5,0$ e $8,0 \mathrm{dS} \mathrm{m}^{-1}$. Em conseqüência houve aumento da soma de bases (SB) e do índice de saturação por bases (V\%), em função do aumento da condutividade elétrica da água.

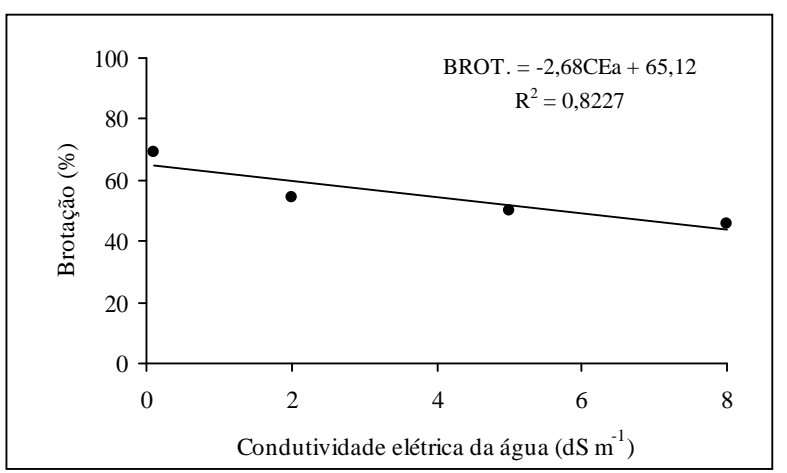

FIGURA 6 - Porcentagem de brotação da cana-de-açúcar em função da salinidade da água de irrigação.

TABELA 3 - Médias das brotações obtidas nas diferentes classes texturais.

\begin{tabular}{lc}
\hline Textura & Brotação $(\boldsymbol{\%})$ \\
\hline Arenosa & $23,98 \mathrm{~b}^{1}$ \\
Média & $67,70 \mathrm{a}$ \\
Argilosa & $79,16 \mathrm{a}$ \\
\hline
\end{tabular}

${ }^{1}$ As médias seguidas pela mesma letra não diferem estatisticamente entre si pelo teste de Scott-Knott. 
TABELA 4-Teores de alguns nutrientes no solo ao final do experimento UFLA, Lavras, MG.

\begin{tabular}{|c|c|c|c|c|}
\hline \multicolumn{5}{|c|}{ Tratamentos (solo arenosos) } \\
\hline Características & $0,1 \mathrm{dS} \mathrm{m}^{-1}$ & $2,0 \mathrm{dS} \mathrm{m}^{-1}$ & $5,0 \mathrm{dS} \mathrm{m}^{-1}$ & $8,0 \mathrm{dS} \mathrm{m}^{-1}$ \\
\hline $\mathrm{pH} \mathrm{em} \mathrm{H}_{2} \mathrm{O}$ & 6,2 & 6,4 & 6,8 & 6,4 \\
\hline $\mathrm{P}\left(\mathrm{mg} \mathrm{dm} \mathrm{dm}^{3-}\right)$ & 87,9 & 67,0 & 90,3 & 87,9 \\
\hline $\mathrm{K}\left(\mathrm{mg} \mathrm{dm^{3- }}\right)$ & 61,0 & 52,0 & 58,0 & 55,0 \\
\hline $\mathrm{Na}\left(\mathrm{mg} \mathrm{dm}^{3-}\right)$ & 27,6 & 463,7 & 883,2 & 1295,4 \\
\hline $\mathrm{Ca}^{+2}\left(\mathrm{cmol}_{\mathrm{c}} / \mathrm{dm}^{3}\right)$ & 3,4 & 2,5 & 2,4 & 2,6 \\
\hline $\mathrm{Mg}^{+2}\left(\mathrm{cmol}_{\mathrm{C}} / \mathrm{dm}^{3}\right)$ & 0,4 & 0,3 & 0,2 & 0,3 \\
\hline $\mathrm{Al}^{+3}\left(\mathrm{cmol}_{\mathrm{c}} / \mathrm{dm}^{3}\right)$ & 0,1 & 0,0 & 0,0 & 0,0 \\
\hline$* \mathrm{SB}\left(\mathrm{cmol}_{\mathrm{c}} / \mathrm{dm}^{3}\right)$ & 4,1 & 4,9 & 6,6 & 8,7 \\
\hline$* \mathrm{t}\left(\mathrm{cmol}_{\mathrm{c}} / \mathrm{dm}^{3}\right)$ & 4,2 & 4,9 & 6,6 & 8,7 \\
\hline$* \mathrm{~T}\left(\mathrm{cmol}_{\mathrm{C}} / \mathrm{dm}^{3}\right)$ & 5,4 & 6,2 & 7,8 & 10,2 \\
\hline$* \mathrm{~V}(\%)$ & 75,8 & 79,2 & 84,6 & 85,3 \\
\hline
\end{tabular}

*SB = soma de bases trocáveis; *t= capacidade de troca catiônica efetiva; * T= capacidade de troca catiônica a pH 7,0; $* \mathrm{~V}=$ índice de saturação por bases.

TABELA 5 - Teores de alguns nutrientes no solo ao final do experimento UFLA, Lavras, MG.

\begin{tabular}{|c|c|c|c|c|}
\hline \multicolumn{5}{|c|}{ Tratamentos (solo média) } \\
\hline Características & $0,1 \mathrm{dS} \mathrm{m}^{-1}$ & $2,0 \mathrm{dS} \mathrm{m}^{-1}$ & $5,0 \mathrm{dS} \mathrm{m}^{-1}$ & $8,0 \mathrm{dS} \mathrm{m}^{-1}$ \\
\hline $\mathrm{pH}$ em $\mathrm{H}_{2} \mathrm{O}$ & 6,4 & 6,5 & 6,3 & 6,2 \\
\hline $\mathrm{P}\left(\mathrm{mg} \mathrm{dm}^{3-}\right)$ & 72,7 & 60,2 & 52,5 & 52,5 \\
\hline $\mathrm{K}\left(\mathrm{mg} \mathrm{dm}^{3-}\right)$ & 56,0 & 63,0 & 70,0 & 89,0 \\
\hline $\mathrm{Na}\left(\mathrm{mg} \mathrm{dm}^{3-}\right)$ & 27,6 & 456,3 & 1140,8 & 1707,5 \\
\hline $\mathrm{Ca}^{+2}\left(\mathrm{cmol}_{\mathrm{c}} / \mathrm{dm}^{3}\right)$ & 5,2 & 5,0 & 5,1 & 4,6 \\
\hline $\mathrm{Mg}^{+2}\left(\mathrm{cmol}_{\mathrm{c}} / \mathrm{dm}^{3}\right)$ & 0,9 & 1,0 & 0,9 & 1,2 \\
\hline $\mathrm{Al}^{+3}\left(\mathrm{cmol}_{\mathrm{c}} / \mathrm{dm}^{3}\right)$ & 0,0 & 0,0 & 0,1 & 0,0 \\
\hline *SB $\left(\mathrm{cmol}_{\mathrm{c}} / \mathrm{dm}^{3}\right)$ & 6,4 & 8,1 & 11,1 & 13,5 \\
\hline$* t\left(\mathrm{cmol}_{\mathrm{c}} / \mathrm{dm}^{3}\right)$ & 6,4 & 8,1 & 11,2 & 13,5 \\
\hline$* \mathrm{~T}\left(\mathrm{cmol}_{\mathrm{c}} / \mathrm{dm}^{3}\right)$ & 7,9 & 9,6 & 12,6 & 15,0 \\
\hline$* \mathrm{~V}(\%)$ & 80,9 & 84,4 & 88,1 & 90,0 \\
\hline
\end{tabular}

*SB = soma de bases trocáveis; * $\mathrm{t}=$ capacidade de troca catiônica efetiva; * $\mathrm{T}=$ capacidade de troca catiônica a pH 7,0;

$* \mathrm{~V}=$ índice de saturação por bases.

TABELA 6 - Teores de alguns nutrientes no solo ao final do experimento UFLA, Lavras, MG.

\begin{tabular}{|c|c|c|c|c|}
\hline \multicolumn{5}{|c|}{ Tratamentos (solo argiloso) } \\
\hline Características & $0,1 \mathrm{dS} \mathrm{m}^{-1}$ & $2,0 \mathrm{dS} \mathrm{m}^{-1}$ & $5,0 \mathrm{dS} \mathrm{m}^{-1}$ & $8,0 \mathrm{dS} \mathrm{m}^{-1}$ \\
\hline $\mathrm{pH} \mathrm{em} \mathrm{H}_{2} \mathrm{O}$ & 6,2 & 6,1 & 6,0 & 6,0 \\
\hline $\mathrm{P}\left(\mathrm{mg} \mathrm{dm}^{3-}\right)$ & 58,3 & 48,4 & 51,1 & 54,0 \\
\hline $\mathrm{K}\left(\mathrm{mg} \mathrm{dm}^{3-}\right)$ & 30,0 & 52,0 & 69,0 & 91,0 \\
\hline $\mathrm{Na}\left(\mathrm{mg} \mathrm{dm}^{3-}\right)$ & 20,2 & 537,7 & 1273,3 & 2001,9 \\
\hline $\mathrm{Ca}^{+2}\left(\mathrm{cmol}_{\mathrm{c}} / \mathrm{dm}^{3}\right)$ & 7,1 & 6,4 & 6,6 & 6,8 \\
\hline $\mathrm{Mg}^{+2}\left(\mathrm{cmol}_{\mathrm{c}} / \mathrm{dm}^{3}\right)$ & 3,0 & 2,4 & 2,6 & 2,9 \\
\hline $\mathrm{Al}^{+3}\left(\mathrm{cmol}_{\mathrm{C}} / \mathrm{dm}^{3}\right)$ & 0,0 & 0,1 & 0,1 & 0,0 \\
\hline *SB $\left(\mathrm{cmol}_{\mathrm{c}} / \mathrm{dm}^{3}\right)$ & 10,3 & 11,3 & 14,9 & 18,6 \\
\hline$*_{\mathrm{t}}\left(\mathrm{cmol}_{\mathrm{c}} / \mathrm{dm}^{3}\right)$ & 10,3 & 11,4 & 15,0 & 18,6 \\
\hline$* \mathrm{~T}\left(\mathrm{cmol}_{\mathrm{c}} / \mathrm{dm}^{3}\right)$ & 12,9 & 13,6 & 18,5 & 21,2 \\
\hline *V $(\%)$ & 79,8 & 83,1 & 80,6 & 87,8 \\
\hline
\end{tabular}

*SB $=$ soma de bases trocáveis; $*$ t= capacidade de troca catiônica efetiva; $* \mathrm{~T}=$ capacidade de troca catiônica a $\mathrm{pH} 7,0$;

$* \mathrm{~V}=$ índice de saturação por bases. 


\section{CONCLUSÕES}

Foi constatado uma redução linear da evapotranspiração da cana-de-açúcar em sua fase inicial de desenvolvimento, com o aumento da salinidade da água de irrigação, sendo esta uma resposta linear independente da classe textural. A maior redução foi verificada em solos arenosos.

Com o aumento da condutividade elétrica da água de irrigação houve incremento na salinidade do solo caracterizada pela condutividade elétrica do extrato de saturação, sendo que em solos argilosos houve os maiores valores.

As variáveis vegetativas apresentaram crescimento inversamente proporcional à concentração de sais na de irrigação, apresentando, entretanto, maiores valores em solos de textura média.

Quanto maior o nível de sal na água de irrigação, maiores os teores de sódio no solo ao final da experimentação, bem como o do índice de saturação por bases.

\section{REFERÊNCIAS BIBLIOGRÁFICAS}

AYERS, R. S.; WESTCOT, D. W. A qualidade da água na agricultura. Campina Grande: UFPB, 1991. 218 p.

BERNARDO, S. Manual de irrigação. 6. ed. Viçosa: UFV, 1996. $596 \mathrm{p}$.

BLANCO, F. F. Tolerância do pepino enxertado à salinidade em ambiente protegido e controle da salinização do solo. 1999. 104 f. Dissertação (Mestrado em Irrigação e Drenagem) - Escola Superior de Agricultura "Luiz de Queiroz”, Piracicaba, 1999.

BORELLA, J. E. Efeito da irrigação com água salina e da lâmina de lixiviação na produção de feijão (Phaseolus vulgaris L.) e na salinização do solo. 1986. 82 f. Dissertação (Mestrado em Irrigação e Drenagem) - Escola Superior de Agricultura “Luiz de Queiroz”, Piracicaba, 1986.
CARVALHO, J. A.; SANTANA, M. J.; QUEIROZ, T. M.; LEDO, C. A. S.; NANNETTI, D. C. Efeitos de diferentes níveis de déficit hídrico e de doses de nitrogênio sobre a produção do pimentão. Revista Brasileira de Engenharia Agrícola e Ambiental, Campina Grande, v. 21, n. 3, p. 262269, 2001.

GERVÁSIO, E. S.; CARVALHO, J. A.; SANTANA, M. J. de. Efeito da salinidade da água de irrigação na produção da alface americana. Revista Brasileira de Engenharia Agrícola e Ambiental, Campina Grande, v. 4, n. 1, p. 125128,2000

LIMA, V. L. A. Efeitos da qualidade da água de irrigação e da fração de lixiviação sobre a cultura do feijoeiro (Phaseolus vulgaris $L$.) em condições de lisímetro de drenagem. 1998. 87 f. Tese (Doutorado em Engenharia Agrícola) - Universidade Federal de Viçosa, Viçosa, 1998.

MARINHO, F. J. L.; FERNANDES, P. D.; GHEYI, H. R. Desenvolvimento inicial do abacaxizeiro, cv. Smooth Cayenne, sob diferentes condições de salinidade da água. Revista Brasileira de Engenharia Agrícola e Ambiental, Campina Grande, v. 2, n. 1 p. 1-5, 1998.

MEDEIROS, J. F. de. Manejo da água de irrigação salina em estufa cultivada com pimentão. 1998. $152 \mathrm{f}$. Tese (Doutorado em Irrigação e Drenagem) - Escola Superior de Agricultura “Luiz de Queiroz”, Piracicaba, 1998.

RICHARDS, L. A. Diagnosis and improvement of saline and alkali soils. Washington: United States Salinity Laboratory, 1954. 160 p. (USDA. Agriculture Handbook, 60).

SOUZA, M. R. de. Comportamento do feijoeiro (Phaseolus vulgaris $L$. CV Eriparza) submetido a diferentes níveis de salinidade da água de irrigação. 1995. 94 f. Dissertação (Mestrado em Engenharia Agrícola) - Universidade Federal de Lavras, Lavras, 1995. 